\title{
The Timely Expression of Myelin Basic Protein Gene in Cultured Rat Brain Oligodendrocytes is Independent of Continuous Neuronal Influences ${ }^{1}$
}

\author{
N. K. ZELLER, ${ }^{2}$ T. N. BEHAR, M. E. DUBOIS-DALCQ, AND R. A. LAZZARINI \\ Laboratory of Molecular Genetics, National Institute of Neurological and Communicative Disorders and Stroke, National Institutes of \\ Health, Bethesda, Maryland 20205
}

\begin{abstract}
The developmental expression of the myelin basic protein (MBP) gene was studied in rat cultured oligodendrocytes using immunofluorescence and in situ hybridization. In newborn rat brain cultures, which contain only glial cells, large amounts of MBP-specific mRNA (as assayed by grain counts in autoradiograms) abruptly accumulated within immature oligodendrocytes 5 to 6 days postnatal. MBP always emerged 6 to 8 days after birth; thus, a week after, galactocerebroside (GC), an early oligodendrocyte marker, had appeared. The percentage of MBP mRNA and MBP-positive cells peaked at about 15 days postnatal and decreased thereafter. The time of emergence of MBP in these cultured oligodendrocytes appears to be determined at a very early stage in their development and independent of continuous neuronal influences. There is a striking correspondence between the times of appearance of MBP in cultured oligodendrocytes and those in the intact animal. Thus, primary cultures made from 5-day prenatal, newborn, and 2-day postnatal animals all express MBP at about the same developmental stage, namely, after 14, 8, and 6 days in culture, respectively. Furthermore, cultured oligodendrocytes obtained from the spinal cord express MBP before those obtained from midbrain or hemispheres, as they would in the intact animal. Thus, the developmental expression of the MBP gene occurs in a similar time frame in vitro and in vivo.

In oligodendrocyte-enriched cultures, where $60 \%$ to $80 \%$ of the cells express MBP, in situ hybridization with the cDNA clone revealed MBP-specific MRNA in the cell body and sometimes in the processes of the differentiated oligodendrocytes. The appearance of MBP-specific RNA in cells previously devoid of it, immediately followed by the appearance of MBP, suggests a control at the level of transcription. Translation may take place in the cell body and processes close to the site of insertion of MBP into myelin membranes, as the mRNA and MBP could be detected in these locations.
\end{abstract}

Received January 10, 1985; Revised April 12, 1985;

Accepted April 12, 1985

\footnotetext{
${ }^{1}$ We wish to thank Drs. R. Fritz, R. Pruss, B. Ranscht, M. E. Franko, P. Marangos, and $D$. Silberberg for the generous gift of antibodies. We also thank Colette Auerswald for her technical assistance. Ray Rusten skillfully printed the micrograph and Judy Hertler typed and edited the manuscript

${ }^{2}$ To whom correspondence should be addressed, at National Institutes of Health, Building 36, Room 4A01, Bethesda, MD 20205
}

Central nervous system (CNS) myelin is a discontinuous, multilamellar membrane sheath surrounding axons that allows fast saltatory conduction in nerve fibers (reviewed in Morell, 1984). One oligodendrocyte, the myelin-forming cell of the CNS, can form an average of 20 to 40 myelin internodes around different axons of the optic nerve (Peters et al., 1976) and, thus, must synthesize large amounts of specific lipids and proteins during myelination. Indeed, the myelin membrane contains approximately $70 \%$ lipids, among which the glycolipid, galactocerebroside (GC), has been identified as specific for the oligodendrocyte membrane (Raff et al., 1978). In the rodent, the relative amounts of the myelin proteins are as follows: $50 \%$ proteolipid (PLP), a hydrophobic transmembrane protein, 30 to $35 \%$ myelin basic protein (MBP), 5\% 2',3'-cyclic nucleotide- $3^{\prime}$-phosphohydrolase (CNP), 1\% myelin-associated glycoprotein (MAG), and several enzymes (reviewed by Norton, 1981).

The best characterized myelin proteins are the MBPs, of which there are four forms in the rodent family (Barbarese el al., 1977; Carnegie and Dowse, 1984). MBP is located in the major dense lines of CNS myelin (Omlin et al., 1982). The primary sequence and partial homology of the two major forms of MBP in rats and mice (18.5 kilodaltons $(\mathrm{kD})$ and $14 \mathrm{kD}$ ) have been determined (Martenson et al., 1971; Durnkley and Carnegie, 1974). The factors or signals which trigger the expression of the genes coding for MBP, as wel as the other myelin proteins, are largely unknown (although CNP is inducible by cAMP in cultured oligodendrocytes) (McMorris, 1984). In the peripheral nervous system, Schwann cells appear to require a continuing signal from neurons to make detectable amounts of myelin-specific components (Mirsky et al., 1980). However, in the CNS the exact role of the neurons in myelin protein synthesis and assembly has not been determined.

We have recently isolated a cDNA clone of mouse MBP, using a family of synthetic oligonucleotides as a primer for cDNA synthesis (Zeller et al., 1984). The sequence of this clone (NZ-112) revealed that it corresponds to the region of the mRNA coding for an amino acid sequence present in all forms of MBP in the mouse. The nucleotide sequence of the cone shows $95 \%$ homology with that published for the rat MBP mRNA (Roach et al., 1983) and, therefore, can be used to detect the MBP mRNA species synthesized in either mouse or rat oligodendrocytes by in situ hybridization techniques. This method is ideal for the study of oligodendrocyte differentiation since it allows one to measure the expression of a particular gene at the level of transcription and to correlate it with the immunofluorescence detection of the protein. The four forms of MBP are recognized immunologically by a monoclonal antibody produced against small mouse MBP, which also reacts with peptide $43-88$ of each MBP and with rat MBP (Fritz and Chou, 1983).

With these tools, we have studied the emergence of MBP mRNA and correlated it with that of MBP in oligodendrocytes during devel 
opment in vivo and in vitro. The advantage of the in vitro system is thal one can obtain populations enriched in brain oligodendrocytes and devoid of neurons (McCarthy and De Vellis, 1980) and, therefore, study developmental events in the absence of the target cell of myelinating oligodendrocytes. Previous studies have demonstrated the presence of MBP in cultured rat oligodendrocytes obtained from fetal or newborn brain, corpus callosum, and oplic nerve (Mirsky et al., 1980; Bologa-Sandru et al., 1981; Roussel et al., 1981, 1983; Bologa et al., 1982, 1983; Pruss et al., 1982), and have revealed that there is a developmental regulation of $\mathrm{MBP}$ in dispersed brain cultures in the absence of myelin formation (Barbarese and Pfeiffer, 1981).

Here, we show that in rat brain cultures, the MBP gene is first expressed at a time when myelination is starting in the CNS region from which the cells were isolated. The timely expression of MBP occurs regardless of the time at which the cells were dissociated from the CNS tissue. We observed that the MBP-specific mRNA is first detected in brain oligodendrocytes between days 5 and 6 postnatal, that large amounts of RNA accumulate in the cell within a 24-hr period, and that the protein is synthesized within the following $48 \mathrm{hr}$, at a time when MBP has been first detected in rat brain in vivo (Sternberger et al., 1978a; Roussel and Nussbaum, 1981). Thus, the primary regulation of MBP synthesis during oligodendrocyte differentiation is probably at the level of transcription and occurs on schedule in the absence of neurons.

\section{Materials and Methods}

Cultures. Primary rat brain cultures were obtained by the methods of McCarthy and De Vellis (1980) and Barbarese and Pfeiffer (1981). Fifteen to 17-day-old Sprague-Dawley rat fetuses or newborns 0 to 4 days of age were decapitated, and their brain hemispheres were removed. In some experiments, the midbrain and spinal cord were also removed and cultured separately. The CNS tissues freed of meninges were soaked in Eagle's minimum essential medium-HEPES, gently dissociated mechanically by pipetting, and filtered through $130 \mu$ and $33 \mu$ Nitex (Tetko Inc., Elmsford, NY). The resultant dispersed cells were seeded at a density of $4 \times 10^{5}$ cells $/ \mathrm{cm}^{2}$ in Falcon or Costar $75-\mathrm{cm}^{2}$ plastic flasks, in $35-\mathrm{mm}$ Petri dishes, or on 13 $\mathrm{mm}$-wide glass coverslips which had been precoated with $0.1 \mathrm{mg} / \mathrm{ml}$ of polyL-lysine, as described (Raff et al., 1979). The medium consisted of Dulbecco's modified Eagle's medium with gentamycin $(25 \mu \mathrm{g} / \mathrm{ml})$, glucose $(1.5 \mathrm{gm} / \mathrm{liter})$, and glutamine $(2 \mathrm{~mm})$. To this basic medium, we added $50 \mu \mathrm{g} / \mathrm{ml}$ of transferrin, $5 \mu \mathrm{g} / \mathrm{ml}$ of insulin, $30 \mathrm{~nm}$ selenium, $5 \mathrm{~nm}$ tri-iodothyronine (T3), 20 nM progesterone, and 20 nM hydrocortisone, modified from the method of Bottenstein and Sato (1979). This medium was then enriched with $5 \%$ hybridoma-selected fetal calf serum (FCS) (medium A). In recent experiments we used medium $B$, which contained the same basic medium enriched with $5 \%$ FCS and transferrin, insulin, and selenium, at the concentrations described above, and 30 nм T3 (Eccleston and Silberberg, 1984).

Enriched oligodendrocyte cultures were obtained by a modification of the method of McCarthy and De Vellis (1980), as advised by F. A. McMorris (personal communication). Briefly, the brains of 2-day-old newborn rats were removed, dissociated, and grown as described above in $75-\mathrm{cm}^{2}$ plastic flasks. After 8 to days in vitro, when the process-bearing cells had positioned themselves over a continuous layer of astrocytes, the cells were put on a rotary shaker overnight at $37^{\circ} \mathrm{C}$, at a speed of $250 \mathrm{rpm}$. The cells which detached by the shaking were washed, spun down, and filtered through 33 $\mu$ Nitex. Thcy wcre subsequently allowed to adhere to plastic $150-\mathrm{cm}^{2}$ flasks at $20^{\circ} \mathrm{C}$ for $10 \mathrm{~min}$. During that time, most of the remaining flat cells adhered to plastic, whereas the small round cells did not. These cells were decanted, washed, and seeded at a density of $5 \times 10^{4}$ to $1.5 \times 10^{5} / \mathrm{cm}^{2}$ on poly-t. lysine-coated glass coverslips or 35-mm Petri dishes as described above. In some experiments, laminin $(10 \mu \mathrm{g} / \mathrm{ml}$ ) was used to coat coverslips (McGarvey et al., 1984). The defined medium enriched in 5\% FCS, as described above, was used to grow these cultures. The relative amount of oligodendrocytes and astrocytes in these cultures was assayed by immunofluorescence using GC and glial fibrillary acidic protein (GFAP) as markers (Mirsky, 1982), as described below.

Throughout this paper, the ages mentioned will not be the in vitro age (except if noted) but the postnatal age. More specifically, the age of the cells will be calculated from the date of birth of the rat (which occurs after 21 days gestation), whether the brain was dissociatcd and cultured before or after birth.
Antibodies and immunolabeling. All antibodies used in these studies were generously given to us by several investigators who had characterized these specific immunogiobulins. Antibodies to rat neuron-specific enolase (NSE) were raised in rabbits (Marangos et al., 1975). A mouse monoclonal IgM antibody reacting to the 200- and $150-\mathrm{kD}$ neurofilament subunits was characterized by Dr. M. E. Franko and found to react with rodent neurons of 15 days fetal age (personal communication). The anti-GC was a mouse hybridoma IgG characterized by Ranscht et al. (1982). A rabbit anti-GC prepared following the method of Fry et al. (1976) was a gift of Dr. D. Silberberg. The MBP antibody was a mouse hybridoma $\lg G$ developed against the small mouse MBP by Fritz and Chou (1983). The antibody to GFAP was a polyclonal rabbit antibody characterized by Pruss (1979) which labeled both astrocyte types I and II (Raff et al., 1983a)

The immunofluorescence labeling methods have been described in these studies. Briefly, NSE was stained after fixation in formaldehyde, glutaraldehyde, and picric acid as described by Schmechel et al. (1980). For GC labeling, the monolayer of living cells was first incubated in dilutions of the monoclonal antibody, followed by incubation with a goat anti-mouse rhodamine (Cappel Laboratories, Cochransville, PA). Cells were subsequently fixed in acid alcohol and either directly examined in the fluorescence microscope or rinsed in serum-containing medium and subsequently incubated with dilutions of rabbit antiserum to GFAP, followed by goat anti-rabbit fluorescein conjugate (Cappel Laboratories). This procedure results in a double labeling of the cells on the same coverslips: oligodendrocytes are stained in rhodamine mode and astrocytes are stained in fluorescein mode. The MBP staining was performed after acid alcohol fixation and could also be combined with staining of GFAP in a similar double-labeling experiment. However, for MBP labeling alone, $4 \%$ formaldehyde could also be used as a fixative for $20 \mathrm{~min}$, followed by a brief treatment with $0.1 \%$ Triton $X$ for 10 min and subsequent staining with MBP mouse monoclonal antibody and goat anti-mouse rhodamine conjugate (Cappel Laboratories). Finally, double labeling for $\mathrm{GC}$ and MBP was performed with dilutions of rabbit anti-GC on living cells, followed by goat anti-rabbit fluorescein, acid alcohol fixation and MBP staining as above. All preparations were examined in a Zeiss Photoscope III, equipped with epifluorescence and appropriate filters for rhodamine and fluorescein.

Labeling of MBP cDNA clone. Either pNZ-111 or pNZ-112, a derivative of pNZ-111 with Xho-1 linkers, was used to prepare the probes (Zeller et al., 1984). Both clones code for the region of MBP corresponding to amino acids 60 to 93, which is present in each of the four rodent MBPS. The CDNA, which was cloned into the Pst-1 site of pBR322, was separated from $\mathrm{pBR} 322$ by get electrophoresis after Pst-1 digestion. The purified insert was then cleaved with Hae III which generated two fragments. Twenty to $25\left[{ }^{35} \mathrm{~S}\right] \mathrm{dATP}$ residues (New England Nuclear, Boston, MA) were added to each of the four $3^{\prime}$ ends of the two fragments using the enzyme terminal deoxynucleotidyltransferase (Deng and Wu, 1981). With this procedure, specific activities of approximately $1 \times 10^{9} \mathrm{dpm} / \mu \mathrm{g}$ of DNA were obtained. The final sizes of the probe pieces with $\left[{ }^{35} \mathrm{~S}\right.$ ]dATP tails were approximately 75 to 100 nucleotides

In situ hybridization. Our procedure is derived from those described by Brahic and Haase (1978) and by Brigati et al. (1983). Brain cells were seeded on coverslips treated as follows: $3 \mathrm{hr}$ soaking in $3 \times$ SSC $(1 \times$ SSC consists of $15 \mathrm{~mm}$ sodium citrate and $150 \mathrm{~mm}$ sodium chloride) and $1 \times$ Denhardt's $\left(0.02 \%\right.$ Ficoll, polyvynylpyrolidone, and bovine serum albumin) at $65^{\circ} \mathrm{C}$, followed by a 30 -min treatment with a 3.1 mixture of absolute alcohol and glacial acetic acid. Finally, coverslips were treated with acetic anhydride to acetylate traces of insoluble protein (Hayashi et al., 1978). The brain cells grown on the coverslips were fixed with $4 \%$ formaldehyde in phosphatebuffered saline (PBS) for $20 \mathrm{~min}$, washed in PBS, incubated for $20 \mathrm{~min}$ in 0.2 $\mathrm{N} \mathrm{HCl}$, washed again, and, in some cases, treated with pronase at $0.01 \mathrm{mg} /$ $\mathrm{ml}$. The coverslips with cells were then dehydrated through a series of graded alcohol solutions containing $300 \mathrm{~mm}$ ammonium acetate and then glued to a coverslide with the cells face up using a special autoslide adhesive (Technicon). Each mounted coverslip was incubated in a humid chamber for $30 \mathrm{hr}$ at $30^{\circ} \mathrm{C}$ with $6 \mu \mathrm{l}$ of a hybridization mIx containing the following components: denatured Escherichia coli DNA $(100 \mu \mathrm{g} / \mathrm{ml})$, deionized formamide $(50 \%), 2 \times$ SSC, $1 \times$ Denhardt's, and $400 \mathrm{~nm}$ of $\mathrm{d}(\mathrm{pT}) 8$ (Collaborative Research, inc., Research Triangle Park, NC). The thymidine octamer was used to block any nonspecific hybridization due to the poly-A tails of the probe. To this mixture was added the ${ }^{35} \mathrm{~S}$-labeled CDNA to a final amount of $3 \times 10^{5} \mathrm{cpm} /$ coverslip. Before it was applied to the coverslips, the hybridization mix was first incubated for 15 to $30 \mathrm{~min}$ at $50^{\circ} \mathrm{C}$, then denatured at $100^{\circ} \mathrm{C}$ for $3 \mathrm{~min}$, quenched on ice, reincubated for $15 \mathrm{~min}$ at $50^{\circ} \mathrm{C}$, and finally added to the dried cells. After the overnight $30^{\circ} \mathrm{C}$ incubation, the slides were washed in a shaker bath three times with $1 \times$ SSC and $50 \%$ formamide for $45 \mathrm{~min}$ at room temperature and then two times at $45^{\circ} \mathrm{C}$ for $10 \mathrm{~min}$ in $2 \times$ SSC. The slides were then rinsed in deionized water and dehydrated through 
a graded series of alcohol with $300 \mathrm{~mm}$ ammonium acetate and air dried. Immediately thereafter the slides were dipped in a 1:1 mixture of Kodak NTB2 emulsion and $600 \mathrm{~mm}$ ammonium acetate melted at $42^{\circ} \mathrm{C}$. The emulsioncoated slides were then dried and put in the refrigerator for 3 days before being developed using standard procedures. After extensive washing, the slides were counterstained with cresyl violet, dehydrated, and mounted for light microscopic examination in a Zeiss Photoscope III with a $\times 63$ objective.

Controls for hybridization specificity included cultures containing $99 \%$ astrocytes and pancreatic ribonuclease A-treated primary brain cultures, and oligodendrocyte-enriched cultures. The cells in these control preparations did not hybridize with the MBP probe. Grain counts were performed using a scaled reticule in the light microscope ocular. To count the total number of grains associated with a cell, it was necessary to correct for the cell thickness by focusing on two planes successively during the counting. The total number of grains obtained for a defined surface of an oligodendrocyte or flat cell was divided by the number of grains seen on an equivalent bare surface of the coverslip near the cells being counted. This ratio of cell grains to background was then used to determine the presence of MBP-specific mRNA (Arnold, 1981). Oligodendrocytes were identified for grain counts by the distinct web-like morphology of their processes. Grain counts were also done on non-oligodendrocyte cells which consisted primarily of fibroblasts and astrocytes.

\section{Results}

Comments on the choice of media and method for culturing brain oligodendrocyte

Media. We have extensively used the defined medium described by Bottenstein and Sato (1979). However, we have deleted the putrescine since its use is not compatible with FCS and added T3 (medium A), which may play an important role in triggering oligodendrocyte differentiation (Bhat et al., 1981b; Eccleston and Silberberg, 1984). We added $5 \%$ FCS to improve the early adhesion and growth of primary brain cultures. While we were performing experiments on rat brain cells grown in medium $A$, reports appeared describing the inhibitory effects of $10 \%$ FCS in medium on oligodendrocyte differentiation (Raff et al., 1983b). In addition, Eccleston and Silberberg (1984) found that optimal oligodendrocyte differentiation could be obtained in defined medium containing only transferrin, insulin, selenium, and T3. This medium, enriched with $5 \%$ FCS (medium B), was used in recent experiments. At similar serum concentrations, medium $A$ yielded approximately $5 \%$ GC + cells, whereas medium $B$ yielded 10 to $15 \%$. The lower number of oligodendrocytes in medium A may be related to the presence of $20 \mathrm{~nm}$ hydrocortisone. Michler-Stuke and Bottenstein (1982) have indeed shown that hydrocortisone at concentrations above $10 \mathrm{~nm}$ may inhibit the growth of certain neural cell lines.

Detection of neurons. Neurons were not detected in the primary brain cultures started from 2- to 3-day-old rats by immunolabeling with antisera to both NSE and neurofilaments. Using morphological criteria, McCarthy and De Vellis (1980) reported similar results. In contrast, NSE-positive cells were observed in 15- to 17-day fetal age brain cultures; however, the numbers decreased to less than $5 \%$ of the total cell population after 10 days in culture. Neurons were not detected in the enriched oligodendrocyte cultures.

Enriched oligodendrocyte cultures. Although the "shaking method" introduces a discontinuity in the culturing process, the oligodendrocyte differentiation in vitro can be adequately followed

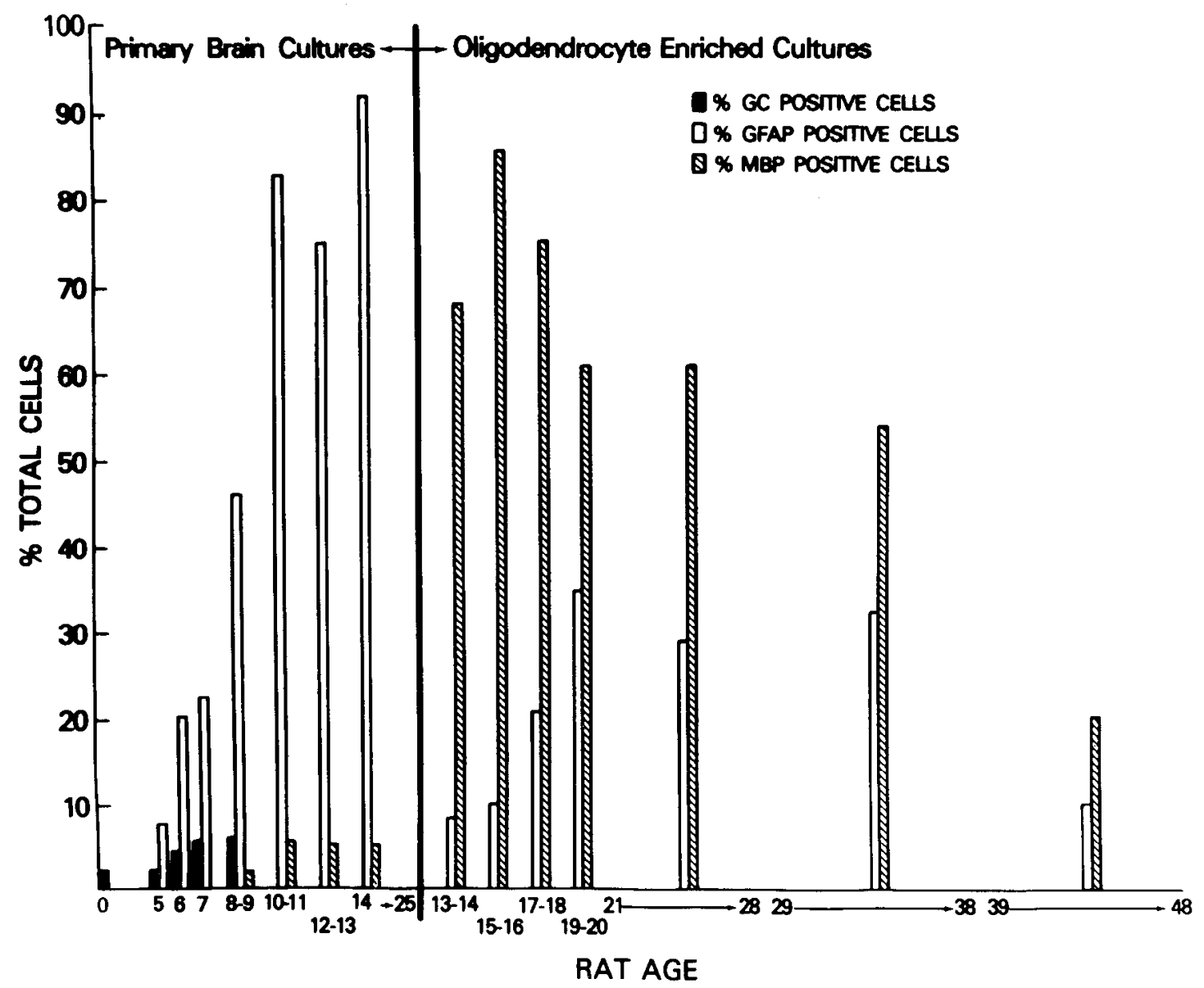

Figure 1. Relative percentage of oligodendrocytes and astrocytes in brain cultures grown in medium A (see "Materials and Methods") as characterized by immunofluorescence using antibodies to GC, GFAP, and MBP. MBP (hatched bars) first appears in GC+ cells (solid bars) at 8 days postnatal using double immunolabeling. After 10 to 12 days in culture, the same cells are positive for both GC and MBP and are also represenled by halched bars. The percentage of GFAP+ cells is indicated by the open bars. 
for a few weeks with this technique. In primary brain cultures, the early growth and differentiation of oligodendrocytes occur harmoniously, but their late maintenance is hampered by the overgrowth of astrocytes and fibroblasts. A similar situation is seen for differentiation of neurons in culture but, in this case, the use of antimitotic drugs allows long-term neuronal development without any damage to this cell type (Ransom et al., 1977). However, antimitotic agents have been shown to delay oligodendrocyte differentiation (Younkin and Silberberg, 1976). Therefore, the shaking method is a simple way to reseed oligodendrocytes in higher relative numbers and gives them more space to continue their differentiation process. This may set them back for a few days but finally allows long term survival and differentiation in vitro.

\section{Emergence and evolution of MBP expression in primary and enriched oligodendrocyte cultures}

The emergence of MBP in oligodendrocytes (defined as GCpositive (+) cells) was analyzed in both primary brain cultures and enriched oligodendrocyte cultures (Fig. 1). As described earlier (Raff et al., 1978; Mirsky et al., 1980; Abney et al., 1981; Eccleston and Silberberg, 1984), GC was found in dissociated brain cells at the time of seeding (days 0 to 2). In the primary brain cultures, the GC+ cells stayed round in shape and immature for a few days. Later, they developed processes which became long and extensive after 1 week in vitro. In these cultures, MBP was first detected by immunofluorescence in the cell bodies of a few GC+ cells at 8 to 9 days postnatal (Fig. 2). This is earlier than described in other studies (Barbarese and Pfeiffer, 1981; Bologa-Sandru et al., 1981; Bologa et al., 1982, 1983). The number of MBP+ cells increased to 5 to $7 \%$ of the primary brain cultures and then remained constant. Using double immunolabeling, we found that MBP staining of the oligodendrocyte processes increased with time, and at 10 to 13 days postnatal, all GC + cells were MBP+, as observed previously (Mirsky et al., 1980; Pruss et al., 1982). These cells were stratified over a heavy layer of GFAP+ cells ( 75 to $80 \%$ ), corresponding primarily to type I astrocytes (Raff et al., 1983a).
Figure 2. Immunofluorescence staining of MBP in primary cultures $(A)$ and in enriched oligodendrocyte cultures $(B)$ at 9 days postnatal $(A)$ and 15 days postnatal $(B)$. At 9 days MBP is visualized mostly in the cell body and much less in the short processes. At 15 days, the oligodendrocytes have acquired multiple processes with some MBP stain and, in some cases, unruffled membranes $(m)$ are also stained. Magnification $\times 350$.
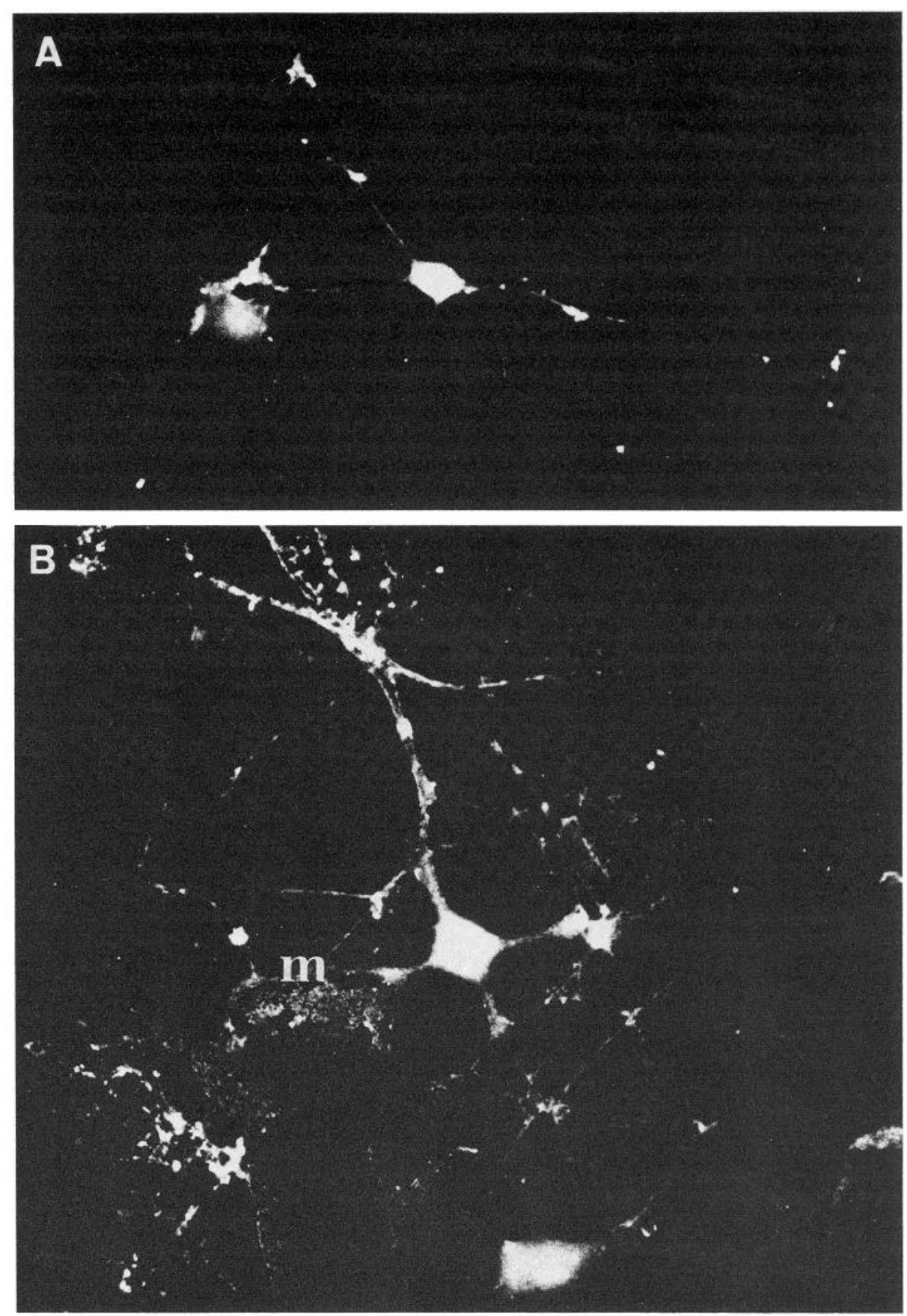
The percentage of cells staining for MBP in the enriched cultures peaked at 13 to 14 days postnatal. We routinely found 60 to $80 \%$ MBP-positive cells together with 8 to $15 \%$ GFAP+ cells that had long slender processes and probably corresponded to type II astrocytes (Raff et al., 1983a). However, during the third week, GFAP+ cells increased to $50 \%$ whereas the percentage of MBP+ cells declined. After 25 days, the percentage of GFAP+ cells also decreased whereas cells negative for all three markers (probably fibroblasts) increased.

Time of emergence of MBP in cultured oligodendrocyte is determined by the rat age and the anatomical region of the CNS

Whether the primary cultures were started from the brain hemispheres of 16-day fetuses or 0- to 3-day-old newborns, the first $\mathrm{MBP}+$ cells were always detected at day 8 to 9 (postnatal) in experiments where cells were grown in medium A (Table I). Earlier expression ( 6 days) was observed in cells grown in medium B (Table II). This time of emergence corresponded to the time at which MBP was first seen in the brain of normal rats (Sternberger et al., 1978a, b). A similar "on schedule" expression of GC at the time of birth was observed in our cultures as described previously (see "Emergence and evolution of MBP expression," above). Thus, GC always precedes the expression of MBP by approximately 1 week. Similar observations have been reported on optic nerve in which synchronized myelination starts during the second week after birth (Mirsky et al., 1980).

When three different areas of CNS of one newborn litter were dissociated and cultured in the same medium (B) at the same time, MBP was detected in the spinal cord-derived cells at least 3 days before the midbrain and hemisphere cultures (Table II). It took 3 to 4 more days for the number of MBP+ cells to coincide with the number of GC+ cells in the spinal cord and hemisphere cultures, whereas it took only 1 day in the midbrain-derived cells. This suggests a greater amount of synchronization of MBP expression in the midbrain than in the other CNS regions.

\section{The appearance of MBP-specific MRNA during oligodendrocyte maturation}

MBP-specific RNA could be detected 2 days before the appearance of MBP immunofluorescence when parallel coverslips of primary cultures were analyzed by in situ hybridization and by immunofluorescence. On day 5 (postnatal) only background levels of grains were found on the brain cells, but in the following 24-hr period, 4 to $5 \%$ of the cells became labeled with the cDNA MBP probe (Fig. $3)$. These cells had an excentric nucleus, as described for immature oligodendrocytes, and showed a ratio of cell grains to background

TABLE ।

Time of appearance of MBP in vitro

\begin{tabular}{lcc}
\hline $\begin{array}{c}\text { Age at which Cells were } \\
\text { Dissociated }\end{array}$ & In Vitro Age & Postnatal Age \\
\hline & \multicolumn{2}{c}{ days } \\
16-day-old fetus $(-5)$ & 14 & 9 \\
Birth & 8 & 8 \\
2 days & $6-7$ & $8-9$ \\
3 days & 6 & 9 \\
\hline
\end{tabular}

${ }^{a}$ Cultures were grown in medium A (see "Material and Methods").

TABLE ॥

$M B P$ expression in cells derived from different areas of the newborn rat $C N S^{a}$

\begin{tabular}{llc}
\hline & $\begin{array}{c}\text { Time of MBP } \\
\text { Emergence }\end{array}$ & $\begin{array}{c}\text { Time when All GC+ } \\
\text { Cells are MBP+ }\end{array}$ \\
\hline Spinal cord & before 3 days & 6 days \\
Midbrain & 6 days & 7 days \\
Hemisphere & 6 days & 10 days \\
\hline
\end{tabular}

${ }^{a}$ Cultures were grown in medium B (see "Materials and Methods").

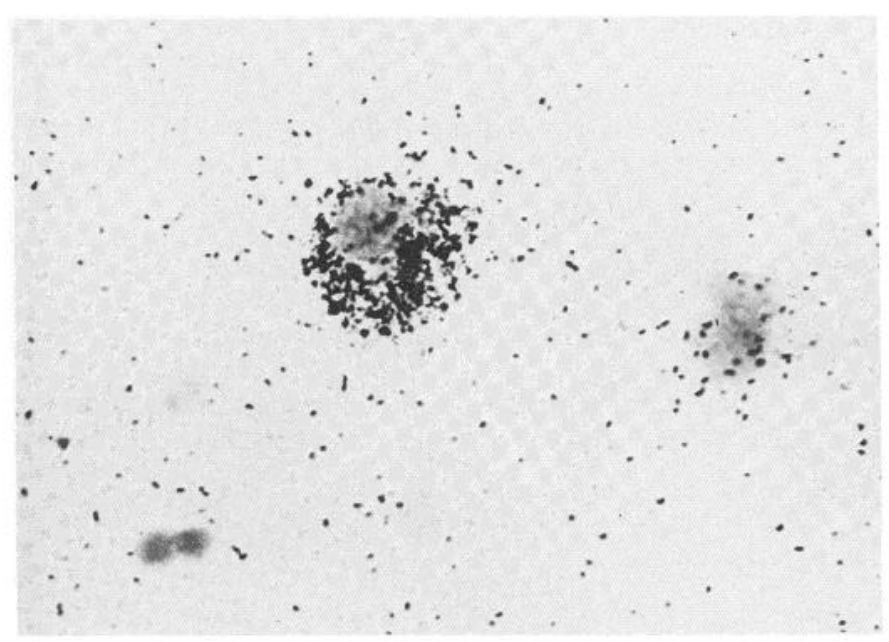

Figure 3. Autoradiogram obtained after in situ hybridization with an MBP. specific cDNA probe on a 7-day postnatal rat primary culture. Note numerous grains (about 6 to 8 times more than background) on a round cell with an excentric nuclei, reminiscent of an immature oligodendrocyte. Magnification $\times 600$.

grains of approximately 5 as compared to 1 in the non-oligodendrocyte cells. This ratio increased to 8 within the next day and stayed at that level until day 15 (postnatal) (Table III). After shaking, this ratio decreased by half, possibly because of some physical damage to the cells during this process, but then increased again and varied between 4 and 6 until day 31 . The ratio for the non-oligodendrocyte cells always was between 1 and 2 .

\section{Evolution of MBP-specific mRNA as compared to MBP in primary enriched oligodendrocyte culture}

Between days 6 and 10, the percentage of MBP mRNA+ cells was larger than that of cells with MBP (Fig. 4). These percentages became identical during the second week in culture, but later the percentage of mRNA+ cells declined compared to the proteinpositive cells. The same trend was seen in the enriched oligodendrocyte cultures, but with a delay. The greatest percentage of mRNA+ cells was seen at 15 days postnatal in primary cultures and 18 days in enriched cultures. In the primary culture, the percentage then dropped to 0.5 to $0.7 \%$ and remained at that level through day 23. In the enriched cultures, the percentage of mRNA+ cells was always lower than the percentage of MBP+ cells. A frequent feature of the in situ hybridization preparations with enriched oligodendrocytes culture was the association of grains with the long slender processes of mature cells (Fig. 5).

\section{Discussion}

The goal of the present study was to determine when the MBP gene is transcribed relative to oligodendrocyte differentiation in an in vitro system devoid of the oligodendrocyte target cell, the neuron. Immunofluorescence and in situ hybridization with antisera and probes which detect the four forms of MBP mRNA and protein, respectively, appeared to be the optimal methods for such a study. The development and differentiation of oligodendrocytes in dispersed cultures were found to be very similar to the process in vivo.

A striking observation is that MBP is always detected first by immunofluorescence at 6 to 8 days postnatal in brain-derived oligodendrocytes. A similar timing of MBP appearance is observed in vivo in the anterior commissure and other brain regions (Sternberger et al., 1978a, b; Roussel and Nussbaum, 1981). The cultured oligodendrocytes appear to follow their natural schedule for MBP expression, regardless of the time at which they were separated from the animal brain and from the neurons. A similar observation has been made for the early marker of oligodendrocytes, GC (Abney et al., 1981), which consistently emerges around birth (Eccleston 
TABLE III

Ratio of cell grains to background grains

The values listed are the result of grain counts done on individual cultured cells after in situ hybridization with the MBP-specific probe. At least 10 cells were counted from two separate experiments. The means and standard deviations are given in the table. "Oligo" is oligodendrocyte and "Non-Oligos" are cells in the culture that did not have the distinct morphology of oligodendrocytes as described under "Materials and Methods."

\begin{tabular}{|c|c|c|c|c|c|}
\hline \multicolumn{3}{|c|}{ Primary Cultures } & \multicolumn{3}{|c|}{ "Shaken" Cultures } \\
\hline Age (days) & Oligo & Non-Oligo & Age (days) & Oligo & Non-Oligo \\
\hline 3 & $0.90 \pm 1.23$ & $0.63 \pm 0.52$ & 13 & $3.48 \pm 0.89$ & $1.65 \pm 0.55$ \\
\hline 4 & $4.65 \pm 1.39$ & $1.17 \pm 0.92$ & 15 & $5.27 \pm 2.17$ & $1.31 \pm 0.30$ \\
\hline 5 & $8.47 \pm 4.87$ & $1.10 \pm 0.34$ & 16 & $6.20 \pm 1.99$ & $1.60 \pm 0.55$ \\
\hline 6 & $8.05 \pm 3.50$ & $1.07 \pm 0.26$ & 18 & $4.06 \pm 0.98$ & $1.45 \pm 0.41$ \\
\hline 8 & $7.19 \pm 4.42$ & $1.59 \pm 0.78$ & 20 & $6.25 \pm 3.46$ & $1.19 \pm 0.58$ \\
\hline 13 & $7.47 \pm 3.68$ & $1.21 \pm 0.19$ & 24 & $4.55 \pm 2.16$ & $1.20 \pm 0.44$ \\
\hline
\end{tabular}

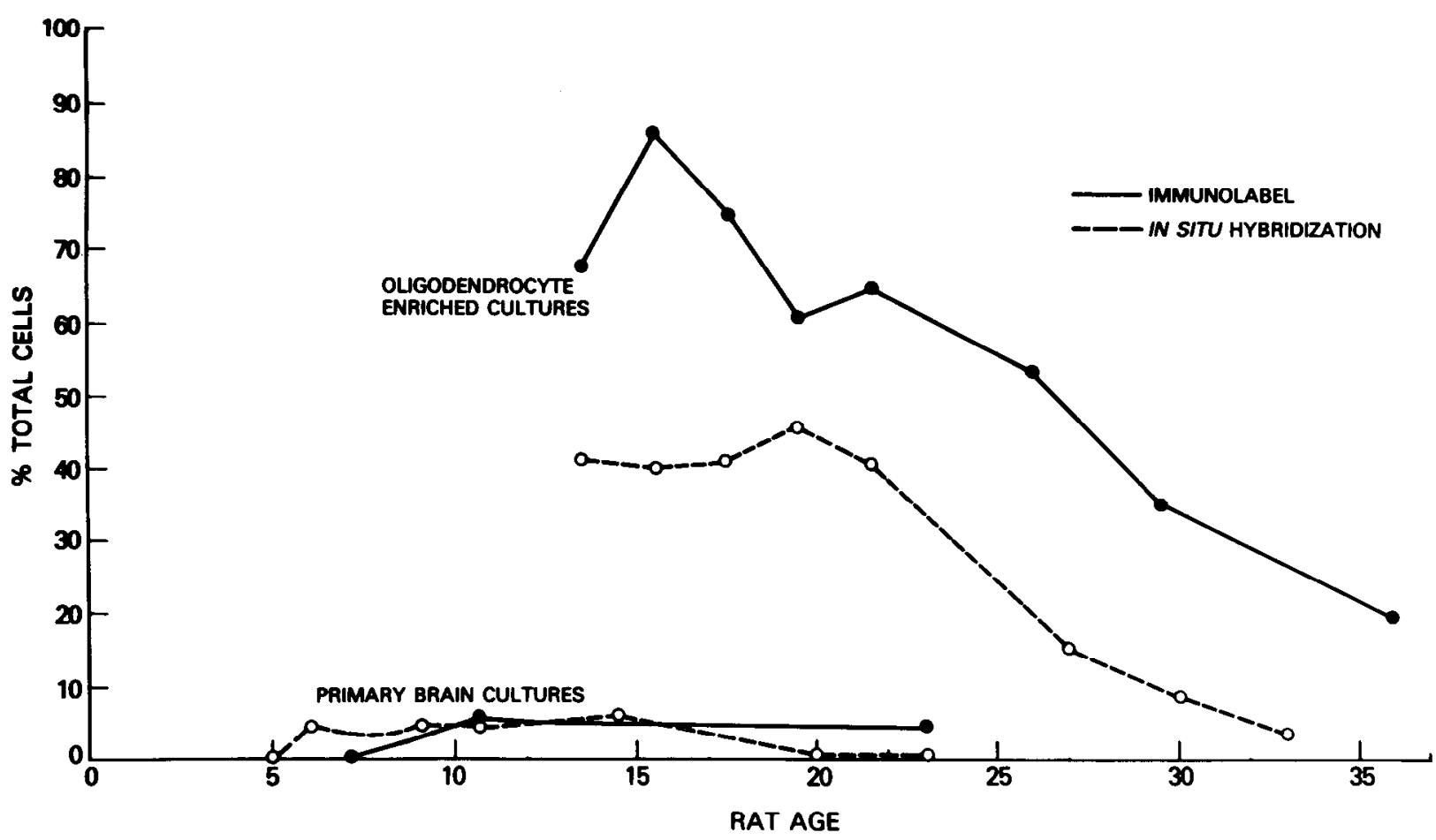

Figure 4. Percentage of rat brain cells expressing MBP as assessed by immunolabeling (solid line) and in situ hybridization (dashed line) on parallel brain cultures. The curves corresponding to the oligodendrocyte-enriched cultures and the primary brain cultures are shown independently. See "Results" for comments.

and Silberberg, 1984). Thus, our observations on MBP confirm that the timely expression of MBP, as well as GC, does not seem to depend on continuous signals from neurons as observed by Mirsky et al. (1980) in optic nerve cultures. It may, however, depend on the presence of non-oligodendrocytic signals (Bhat et al., 1981a), such as type I astrocytes, as was demonstrated recently in optic nerve culture (M. C. Raff, R. H. Miller, and M. Noble, personal communication).

Oligodendrocytes also follow an in vitro timetable for MBP expression corresponding to the start of myelination in the CNS region from which they were isolated. Myelination is known to start first in the spinal cord and to progress in a caudorostral direction (Raine, 1977), although some asynchrony between individual fiber tracts exists. As predicted, the spinal cord-derived oligodendrocytes express MBP several days before the midbrain and the hemisphere, suggesting that regional regulation of MBP expression is maintained in vitro.

Our results from the in situ hybridization study show that between days 5 and 6 (postnatal) large amounts of MBP-specific RNA, as based on grain counts, appear in immature brain-derived oligodendrocytes 2 days before the protein can be detected. It is likely that the delay in detection of protein-positive cells is partly related to differences in sensitivity of detection of mRNA versus protein. Nevertheless, the observation that appearance of MBP mRNA precedes the appearance of MBP itself is consistent with our previous work on the accumulation of MBP mRNA in mouse brain during early development (Zeller et al., 1984). Both findings support the notion that MBP synthesis is regulated at the level of transcription.

During the early stages of oligodendrocyte maturation, more MBP mRNA+ cells are detected than MBP+ cells, but both increase during the next few days. It is very likely that these populations represent identical cells, but it will require double-labeling experiments of both mRNA and protein within the same cell to definitely prove that point. Between 15 and 20 days postnatal, percentages of mRNA+ and MBP+ cells peak, but mRNA+ cells are less numerous than the $\mathrm{MBP}+$ cells. The reason for this difference is obscure at present but may stem from differences in the metabolic stabilities of MBP mRNA and protein. It is also conceivable that the difference is an artifact resulting from the inability to detect a population of MBP mRNA-positive cells by in situ hybridization. interestingly, the greatest percentage of mRNA-positive cells in enriched cultures corresponds closely to the peak level of specific 


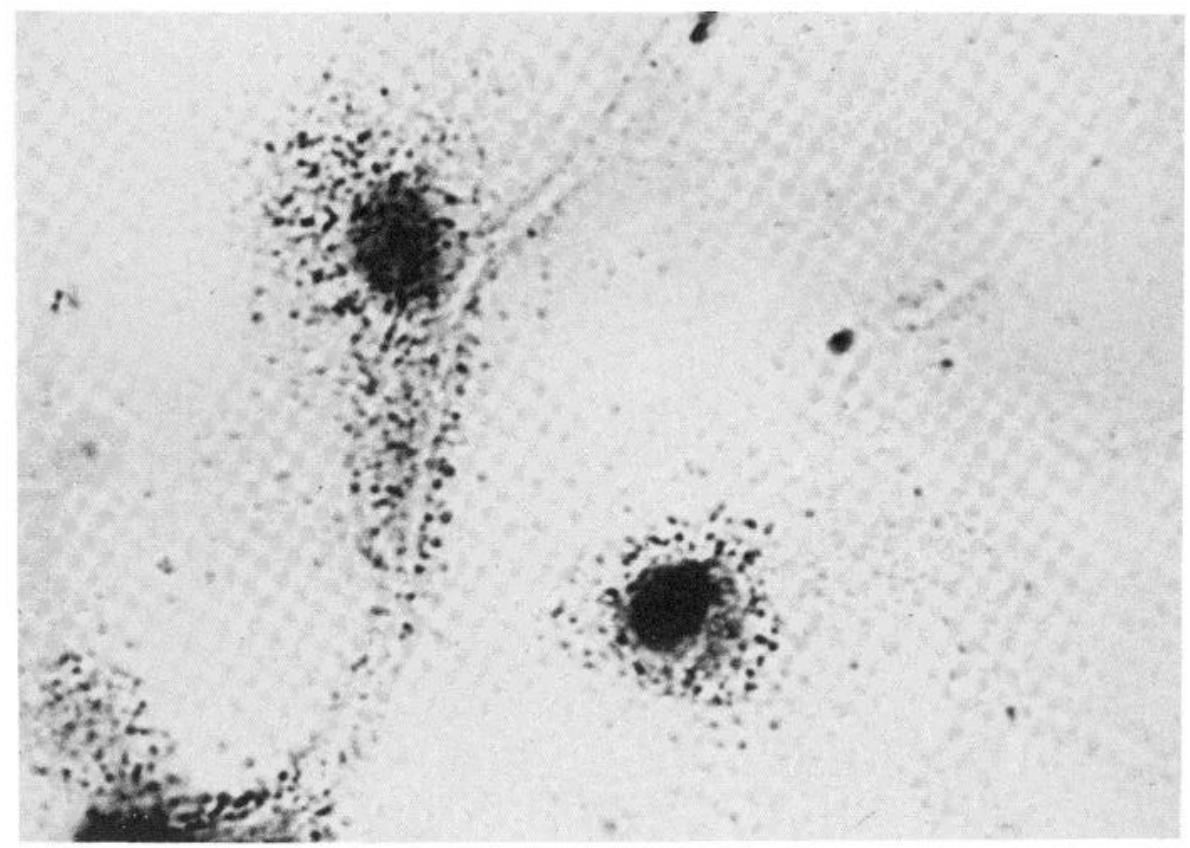

Figure 5. Autoradiogram of an enriched oligodendrocyte culture after in situ hybridization with the MBP-specific cDNA probe. The differentiated oligodendrocytes show an increased number of grains over background on their cell bodies and along their numerous processes. Magnification $x$ 600

mRNA in brain (18 days) (Zeller et al., 1984). The peak of MBP synthesis in vivo also occurs at 18 days postnatal in the mouse (Campagnoni et al., 1978).

The finding of MBP-specific hybridization along oligodendrocyte processes is of interest since each of them will finally form one myelin internode in vitro. These processes contain free ribosomes which may actively synthesize MBP (Campagnoni et al., 1980) on the site of its incorporation in the membrane, as suggested by previous studies (Colman et al., 1983). During the third week, in primary and enriched cultures, both mRNA+ and protein-positive cells decrease progressively in percentage, as described earlier (Massa et al., 1982). A similar decrease in MBP in the cytoplasm of differentiating oligodendrocytes has been observed in vivo by immunocytochemical techniques (Sternberger et al., 1978a; Hartman et al., 1979; Roussel and Nussbaum, 1981). Hartman et al. (1979) estimate that, in one specific tractus, it takes 6 to 12 days to see MBP emerging in the cytoplasm and moving in the processes toward a myelin internode.

In conclusion, the MBP gene is expressed on schedule in oligodendrocytes cultured in the absence of neurons and at a time similar to that observed in vivo in the corresponding region of the CNS. The rise and fall of MBP mRNA and protein in vitro also parallels that observed in vivo. It is possible that the timing of myelin genes expression is determined very early in fetal life. Expression would later be internally regulated and independent of neuronal influence. It would be interesting to elucidate how expression of the genes coding for PLP and MAG, two transmembrane proteins of myelin, are coordinated with that of $\mathrm{GC}$ and MBP in vitro (M. E. DuboisDalcq. T. Behar, L. Hudson, and R. A. Lazzarini, submitted for publication).

\section{References}

Abney, E. R., P. P. Bartlett, and M. C. Raff (1981) Astrocytes, ependymal cells, and oligodendrocytes develop on schedule in dissociated cell cultures of embryonic rat brain. Dev. Biol. 83: 301-310.

Arnold, A. (1981) Quantitative analysis of steroid autoradiograms. J. Histochem. Cytochem. 29: 207-211

Barbarese, E., and S. E. Pfeiffer (1981) Developmental regulation of myelin basic protein in dispersed cultures. Proc. Natl. Acad. Sci. U. S. A. 78: 1953-1956.

Barbarese, E., P. E. Braun, and J. H. Carson (1977) Identification of prelarge and presmall basic proteins in mouse myelin and their structural relationship to large and small basic proteins. Proc. Natl. Acad. Sci. U. S. A. 74: 33603364
Bhat, S., E. Barbarese, and S. E. Pfeiffer (1981a) Requirement for nonoligodendrocyte cell signals for enhanced myelinogenic gene expression in long-term cultures of purified rat oligodendrocytes. Proc. Natl. Acad. Sci. U. S. A. 78: 1283-1287.

Bhat, N. R., G. S. Rao, and R. A. Pieringer (1981b) Investigations on myelination in vitro. Regulation of sulfolipid synthesis by thyroid hormone in cultures of dissociated brain cells from embryonic mice. J. Biol. Chem. 256: $1167-1171$.

Bologa, L., A. Z'Graggen, E. Rossi, and N. Herschkowitz (1982) Differentiation and proliferation: Two possible mechanisms for the regeneration of oligodendrocytes in culture. J. Neurol. Sci. 57: 419-434.

Bologa, L., J. -C. Bisconte, R. Joubert, S. Margules, and N. Herschkowitz (1983) Proliferative activity and characteristics of immunocytochemically identified oligodendrocytes in embryonic mouse brain cell cultures. Exp. Brain Res. 50: 84-90.

Bologa-Sandru, L., H. P. Siegrist, A. Z'Graggen, K. Hofmann, U. Weismann D. Dahl, and N. Herschkowitz (1981) Expression of antigenic markers during the development of oligodendrocytes in mouse brain cell cultures. Brain Res. 210: 217-229.

Bottenstein, J. E., and G. H. Sato (1979) Growth of a rat neuroblastoma cell line in serum-free supplemented medium. Proc. Natl. Acad. Sci. U. S. A. 76: 514-517.

Brahic, M., and A. T. Haase (1978) Detection of viral sequences of low reiteration frequency by in situ hybridization. Proc. Natl. Acad. Sci. U. S A. 75 : 6125-6129.

Brigati, D. J., D. Myerson, J. J. Leary, B. Spalholz, S. Z. Travis, C. K. Y. Fong, G. D. Hsiung, and D. C. Ward (1983) Detection of viral genomes in cultured cells and paraffin-embedded tissue sections using biotin-labeled hybridization probes. Virology 126: 32-50.

Campagnoni, A. T., G. D. Carey, and Y. -T. Yu (1980) In vitro synthesis of the myelin basic proteins: Subcellular site of synthesis. J. Neurochem. 34: 677-686.

Campagnoni, C. W., G. D. Carey, and A. T. Campagnoni (1978) Synthesis of myelin basic proteins in the developing mouse brain. Arch. Biochem. Biophys. 190: 143-150.

Carnegie, P. R., and C. A. Dowse (1984) Partial characterization of $21.5 \mathrm{~K}$ myelin basic protein from sheep brain. Science 223: 936-938.

Colman, D. R., G. Kreibich, A. B. Frey, and D. D. Sabatini (1983) Synthesis and incorporation of myelin polypeptides into CNS myelin. J. Cell Biol. 95: 598-608.

Deng, G. - R., and R. Wu (1981) An improved procedure for utilizing terminal transferase to add homopolymers to the $3^{\prime}$ termini of DNA. Nucleic Acids Res. 9: 4173-4188.

Dunkley, P. R., and P. R. Carnegie (1974) Amino acid sequence of the smaller basic protein from rat brain myelin. Biochem. J. 141: 243-255.

Eccleston, P. A., and D. H. Silberberg (1984) The differentiation of oligodendrocytes in a serum-free, hormone supplemented medium. Dev. Brain Res. 16: 1-9. 
Fritz, R. B and C. - H. Chou (1983) Epitopes of peptide 43-88 of guinea pig myelin protein: Localization with monoclonal antibodies. J. Immunol. 130 : 2180-2183

Fry, J. M., R. P. Lisak, M. C. Manning, and D. H. Silberberg (1976) Serological techniques for detection of antibody to galactocerebroside. J. Immunol. Methods 11: 185-193.

Hartman, B. K., H. C. Agrawal, S. Kalmbach, and W. T. Shearer (1979) A comparative study of the immunohistochemical localization of basic protein to myelin and oligodendrocytes in rat and chicken brain. J. Comp. Neurol. 188: 273-290.

Hayashi, S., I. C. Gillam, A. D. Delaney, and G. M. Tener (1978) Acetylation of chromosome squashes of Drosophila melanogaster decreased the background in autoradiographs from hybridization with ${ }^{125}$-labeled RNA. J. Histochem. Cytochem. 26: 677-679.

Marangos, P. J., C. Zomzely-Neurath, and C. York (1975) Immunological studies of a nerve specific protein (NSP). Arch. Biochem. Biophys. 170: 289.

Martenson, R. E., G. E. Deibler, and M. W. Kies (1971) The occurrence of two myelin basic proteins in the central nervous system of rodents in the suborders Myomorpha and Sciuromorpha. J. Neurochem. 18: 2427-2433.

Massa, P. T., V. L. Friedrich, Jr., and E. Mugnaini (1982) Correlation between fine structural features and immunocytochemical labeling of phase dense cells in primary rat glial cell cultures. J. Cell Biol. 95: 59a, 2124.

McCarthy, K. D., and J. De Vellis (1980) Preparation of scparate astroglial and oligodendroglia cell cultures from rat cerebral tissue. J. Cell Biol. 85 890-902.

McGarvey, M. L., A. Baron-Van Evercooren, H. K. Kleimrnan, and M. DuboisDalcq (1984) Synthesis and effects of basement membrane components in cultured rat Schwann cells. Dev. Biol, 104: 1-11.

McMorris, F. A. (1984) Cyclic AMP induction of the myelin enzyme $2^{\prime}, 3^{\prime}$ cyclic nucleotide $3^{\prime}$-phosphohydrolase (CNP) in rat oligodendrocytes. J. Neurochem. 41: 506

Michler-Stuke, A., and J. E. Bottenstein (1982) Defined media for the growth of human and rat glial-derived cells. Cold Spring Harbor Conf. Cell Proliferation $9: 959-971$

Mirsky, R. (1982) The use of antibodies to define and study major cell types in the central and peripheral nervous system. In Neuroimmunology, $\mathrm{J}$ Brockos, od., pp. 141-181, Plenum Press, New York.

Mirsky, R., J. Winter, E. R. Abney, R. M. Pruss, J. Gavrilovic, and M. C. Raff (1980) Myelin-specific proteins and glycolipids in rat Schwann cells and uliguder idrucytes in culture. J. Cell Biol. 84. 483-494.

Morell, P. (1984) Myelin, Ed. 2, Plenum Publishing Corp., New York.

Norton, W. T. (1981) Biochemistry of Myelin. Adv. Neurobiol. 31: 93-121.

Omlin, F. X., H. deF. Webster, C. G. Haklovitz, and S. R. Cohen (1982) Immunocytochemical localization of basic protein in major dense line regions of central and peripheral myelin. J. Cell Biol. 95: 242-248.

Peters, A., S. L. Palay, and H. deF. Webster (1976) The Fine Structure of the Nervous System: The Neurons and Supporting Cells, W. B. Saunders Co., Philadelphia.

Pruss, R. M. (1979) Thy- 1 antigen on astrocytes in long term cultures of rat central nervous system. Nature 280:688-690.

Pruss, R. M., P. F. Bartlett, J. Gavrilovic, R. P. Lisak, and S. Rattray (1982) Mitogens for glial cells: A comparison of the response of cultured astrocytes, oligodendrocytes and Schwann cells. Dev. Brain Res. 2: 19-35.
Raff, M. C., R. Mirsky, K. L. Fields, R. P. Lisak, S. H. Dorfman, D. H. Silberberg, N. A. Gregson, S. Leibowitz, and M. C. Kennedy (1978) Galactocerebroside is a specific cell-surface antigenic marker for oligodendrocytes in culture. Nature 274: 813-816.

Raff, M. C., K. L. Fields, S. Hakomori, R. Mirsky, R. M. Pruss, and J. Winter (1979) Cell-type-specific markers for distinguishing and studying neurons and the major classes of glial cells in culture. Brain Res. 174: 283-308.

Raff, M. C., E. R. Abney, J. Cohen, R. Lindsay, and M. Noble (1983a) Two types of astrocytes in cultures of developing rat white matter: Differences in morphology, surface gangliosides, and growth characteristics. J. Neurosci. 3: $1289-1300$.

Raff, M. C., R. H. Miller, and M. Noble (1983b) A glial progenitor cell that develops in vitro into an astrocyte or an oligodendrocyte depending on culture medium. Nature 303: 390-396.

Raine, C. S. (1977) Morphological aspects of myelin and myelination. In Myelin, P. Morrell, ed., pp. 1-49, Plenum Press, New York.

Ranscht, B., P. A. Clapshaw, J. Price, M. Noble, and W. Seifert (1982) Development of oliqodendrocytes and Schwann cells studied with a monoclonal antibody against galactocerebroside. Proc. Natl. Acad. Sci. U. S. A. $79: 2709-2713$.

Ransom, B. R., F. Neale, M. Henkart, P. N. Bullock, and P. G. Nelson (1977) Mouse spinal cord in cell culture. I. Morphology and intrinsic neuronal electrophysiologic properties. J. Neurophysiol. 40: 1132-1150.

Roach, $\Lambda$., K. Boylan, S. Horvath, S. B. Prusiner, and L. E. Hood (1983) Characterization of cloned cDNA representing rat myelin basic protein: Absence of expression in brain of Shiverer mutant mice. Cell 34: 799806.

Roussel, G., and J. L. Nussbaum (1981) Comparative localization of Wolfgram $W_{1}$ and myelin basic protein in the rat brain during ontogenesis. Histochem. J. 13: 1029-1047.

Roussel, G., G. Labourdetti, and J. L. Nussbaum (1981) Characterization of oligodendrocytes in primary cultures from brain hemispheres of newborn rats. Dev. Biol. 81: 372-378.

Roussel, G., M. Sensenbrenner, G. Labourdette, E. Wittendorp-Rechenmann, B. Pettmann, and J. -L. Nussbaum (1983) An immunohistochemical study of two myelin-specific proteins in enriched oligodendroglial cell cultures combined with an autoradiographic investigation using ${ }^{3} \mathrm{H}$-thymidine. Dev. Brain Res. 8: 193-203.

Schmechel, D. E., M. W. Brightman, and J. L. Barker (1980) Localization of neuron-specific enolase in mouse spinal neurons grown in tissue culture. Brain Res. 181: 391-400.

Sternberger, N. H. Y. Itoyama, M. W. Kies, and H. deF. Webster (1978a) Myelin basic protein demonstrated immunocytochemically in oligodendroglia prior to myelin sheath formation. Proc. Natl. Acad. Sci. U. S. A. 75. $2521-2524$

Sternberger, N. H., Y. Itoyama, M. W. Kies, and H. deF. Webster (1978b) Immunocytochemical method to identify basic protein in myelin-forming oligodendrocytes of newborn rat C.N.S. J. Neurocytol. 7: 251-263.

Younkin, L. H., and D. H. Silberberg (1976) Delay of oligodendrocyte differentiation by 5-bromodeoxyuridine (BUdR). Brain Res. 101: 600-605.

Zeller, N. K. M. Hunkeler, A. T. Campagnoni, J. Sprague, and R. A. Lazzarini (1984) Characterization of mouse myelin basic protein messenger RNAs with a myelin basic protein cDNA clone. Proc. Natl. Acad. Sci. U. S. A 81: $18-22$ 